\title{
Does insulin resistance co-exist with glucocorticoid resistance in the metabolic syndrome? Studies comparing skin sensitivity to glucocorticoids in individuals with and without acanthosis nigricans
}

\author{
Surujpal Teelucksingh ${ }^{1 *}$, Sarada Jaimungal ${ }^{1}$, Lexley Pinto Pereira ${ }^{3}$, Terence Seemungal ${ }^{1}$ and Shivananda Nayak ${ }^{2}$
}

\begin{abstract}
Background: The metabolic syndrome is associated with increased risk for both diabetes and coronary artery disease, which insulin resistance alone does not satisfactorily explain. We propose an additional and complementary underlying mechanism of glucocorticoid resistance.

Results: Using acanthosis nigricans (AN) and skin vasoconstrictor (SVC) response to topically applied beclomethasone dipropionate as markers of insulin and glucocorticoid resistance, respectively, we compared anthropometric, biochemical, pro-inflammatory markers and the SVC response in subjects with AN in two studies: STUDY 1 was used to compare subjects with AN (Grade $4, n=32)$, with those without AN $(n=68)$ while STUDY 2 compared these responses among a cross-section of diabetic patients $(n=109)$ with varying grades of AN (grade $0, n=30$; grade $1, n=24$; grade $2, n=18$; grade $3, n=25$; grade $4, n=12$ ).

Findings: In both studies there was an inverse relationship between AN Grade 4 and the SVC response, $(P<$ 0.001). In STUDY 1, AN Grade 4 was associated with age, waist circumference, BMI, fasting blood glucose, plasma lipids and hs-CRP $(P<0.05)$. SVC was an independent predictor of CRP and those with combined AN and a negative SVC response, CRP levels were highest. In Study 2 when the SVC response in subjects with type 2 diabetes mellitus with varying degrees of AN was studied, it showed that for any degree of AN, the SVC response is more likely to be negative and was independent of gender and ethnicity.

Conclusion: An absent SVC response represents a new biomarker for the metabolic syndrome and the exaggerated inflammatory response, which characterizes the metabolic syndrome, may be an outcome of deficient glucocorticoid action in vascular tissue.
\end{abstract}

Keywords: Insulin resistance, Glucocorticoid resistance, Acanthosis nigricans, Skin vasoconstrictor test

\section{Introduction}

Cardiovascular disease, the leading cause of death in developed countries for many decades, is gaining fresh momentum from the pandemic of obesity which is an emergent major public health problem in developing countries globally [1]. The long recognized association

\footnotetext{
* Correspondence: pteelucksingh@gmail.com

'Department of Clinical Medical Sciences, The University of the West Indies. St Augustine, Trinidad \& Tobago.W.I

Full list of author information is available at the end of the article
}

between cardiovascular disease and obesity [2] became clearer in 1988 when Reaven [3] consolidated the concept proposing that insulin resistance with compensatory hyperinsulinemia was a fundamental pathogenetic mechanism. Type 2 diabetes mellitus (T2DM), hypertension, dyslipidemia and obesity are, independently and collectively, consistently associated with the hyperinsulinemic - insulin resistance syndrome or what is now commonly referred to as the metabolic syndrome (MS) and 
those with MS experience 2 and 5- fold increases respectively, in risk for T2DM and cardiovascular disease [4].

It is widely accepted that insulin resistance-hyperinsulinemia is a common thread in the MS. However several features such as mood and sleep disturbances, a prothrombotic tendency and elevated levels of inflammatory markers have a consistent yet largely unexplained relationship to insulin resistance so that the full understanding of the dysglycaemia-cardiovascular connection is far from complete [5,6].

A growing body of evidence suggests obesity, per se, may be an inflammatory condition [7] and persons with T2DM, MS or obesity exhibit more pronounced and longer-lasting inflammatory responses to challenge than metabolically normal controls [8]. Chronic inflammation might therefore be the prime mover and common antecedent of both T2DM and atherosclerosis [7-9]. What accounts for the loss of control of inflammation? Is it as Kolb and Mandrup-Poulsen [8] proposed, "a deficiency of counter-regulatory circuits to inflammation and metabolic stress"? Or is it the over-riding presence of obesity which drives inflammation to impair insulin signaling mechanisms and confer insulin resistance [10]?

Cortisol, the naturally occurring glucocorticoid in man and primates, plays a central role in the regulation of inflammation, the immune system, intermediary metabolism, the stress response and the cardiovascular system [11]. Genetic susceptibility to cardiovascular disease has been linked to polymorphisms of the glucocorticoid receptor gene which in the case of haplotype 3, a common genetic variant, gives rise to a highly active proinflammatory system as evidenced by serum C-reactive protein (CRP) which is attributed to diminished sensitivity to cortisol[12]. Thus despite mounting evidence for increased cortisol production [13] and increased cortisol regeneration [14] in the metabolic syndrome. we postulated that cortisol bioactivity is concomitantly diminished in MS as a result of diminished glucocorticoid receptor sensitivity.

To test this hypothesis, we have exploited the human skin because of its ability to exhibit both insulin resistance, (evidenced by the presence of acanthosis nigricans, AN) [15] and glucocorticoid resistance (evidenced by a failed skin vasoconstrictor (SVC) response to topically applied glucocorticoid) [16] and further explored the relationship of these skin markers to inflammation as measured by highly sensitive C-reactive protein (CRP).

\section{Methods and subjects}

Two studies were undertaken. All subjects gave informed, written consent and approval to conduct these studies was obtained from the ethics committee of The University of The West Indies.
DESIGN: Study 1 used a case-control design. Study 2 used a cross-sectional design with convenience sampling.

\section{Sample size}

In the calculation of sample size, the alpha error was set to 0.05 and beta to 0.2 (power of $80 \%$ ). Calculations were based on an odds ratio of 5 (that is, subjects with acanthosis nigricans would be 5 times less likely to respond to topical glucocorticoids) and the aim was to enlist twice as many subjects with acanthosis nigricans as those without. From a prior study, 10\% of controls had no blanching response to the skin vascoconstrictor (SVC) assay [16]. Using these values, it was determined that 30 subjects with acanthosis nigricans and 60 without this particular feature were required.

\section{Subject selection}

STUDY 1 compared subjects at the extreme ends of the spectrum for the physical finding of AN by selecting for comparison those with severe (grade 4) and normal healthy controls without any degree of AN around the neck (grade 0). Grading of severity was based on criteria by Burke et al [15]. Subjects were drawn from the hospital outpatient clinic. Those with AN were recruited as they presented at the diabetic clinic and included patients as well as relatives accompanying them, who may have had no knowledge of their diabetic state. Subjects without AN were drawn from hospital staff, who denied any history of major medical problems.

STUDY 2 used a cross-sectional design to compare subjects with T2DM who were differentiated by the grade of acanthosis nigricans present at the neck, which was scored 0-4 using criteria of Burke et al [15]. In study 2, two subjects refused the SVC assay out of the 109 sampled.

\section{Investigations}

All subjects completed a simple questionnaire, which provided data on age, gender, ethnicity and the presence/ absence of T2DM. Patients were considered diabetic if the fasting blood glucose concentration was $>126 \mathrm{mg} / \mathrm{dl}$ or if they responded "yes" to having T2DM on the questionnaire. In addition, anthropometric measurements including weight, height, and waist circumference were measured. Fasting blood samples were taken, processed and stored at $-20^{\circ} \mathrm{C}$ for subsequent biochemical analyses. Blood levels of TNF-alpha, IL-1, IL-6 were determined by ELISA (GenWay, Biotech, Inc. San Diego) and hs-CRP, plasma glucose and serum triglyceride were measured using a dry chemistry analyzer (Johnson and Johnson Vitros 250 Ortho-Clinical Diagnostics Inc. NY, USA) with the appropriate quality controls. 


\section{Skin vasoconstrictor assay}

The SVC assay was performed according to method described by Brown et al [16]. The test and control solutions were beclomethasone dipropionate (Sigma) dissolved in $95 \%$ ethanol to make a concentration of $1000 \mu \mathrm{g} / \mathrm{ml}$ (10-fold higher than that in the original citation) and $95 \%$ ethanol were stored at $4^{\circ} \mathrm{C}$ until time of use. Two circular outlines on the flexor aspect of the forearm were obtained using double-sided adhesive tape with $2 \mathrm{~cm}$ diameter holes. Ten $\mu \mathrm{l}$ of either test or control solution was applied at random to these sites, allowed to dry, occluded with plastic wrap for 16 hours and 2 hours later observed for blanching under fluorescent light by a trained observer, who was blind to the acanthosis nigricans score and the randomized site of application of test solutions.

\section{Statistical analyses}

The relationships of AN (presence/absence) to the SVC response (presence/absence) or to ethnicity were analyzed by the chi squared test. Other data were analyzed by the Students t- test or Mann Whitney- $U$ test as appropriate. In study 1 , CRP was not normally distributed but had linear relation with parameters measured. A generalized linear model was constructed with serum CRP as outcome variable and variables having significant univariate relationship with CRP as independent variables. Data was analyzed using SPSS version 12 for windows.

\section{Results \\ Study 1 \\ Baseline characteristics}

A total of 100 patients were recruited with mean (SD) age 29.90 (11.87) years, weight 72.99 (21.09) Kg, BMI 25.91 (7.41) $\mathrm{kg} / \mathrm{m}^{2}$. There were 44 males. A SVC response of grade $>0$ to topical steroid was demonstrated in $58 \%$ of subjects. Of the 100 patients recruited, 68 had no acanthosis nigricans and 32 had grade 4 acanthosis nigricans. Table 1 shows a comparison of demographic variables and the SVC assay in subjects with and without acanthosis nigricans.

\section{Ethnicity and $A N$ and SVC}

Tables 2, 3 show that in Study 1 there appears to be a greater tendency for Afro-Caribbeans to have AN grade 4 and an SVC response of grade 0, however the sample of Afro-Caribbeans controls $(n=5)$ and of "others' $(n=10)$ would have precluded meaningful analysis. Tables 4, 5 summarizes the relationships between AN, SVC and ethnicity for all grades of AN and for which there was no apparent ethnic influence on SVC.

\section{AN and SVC}

In Study 1, while $76 \%$ of those without AN responded with a positive SVC only $19 \%$ of subjects with AN grade 4 showed a similar response. Figure 1(a) shows that in Study
Table 1 Demographic and physiologic variables in subjects with acanthosis nigricans (Grade 4) and without acanthosis nigricans (GRADE 0), N = 100

\begin{tabular}{|c|c|c|c|}
\hline \multirow[t]{2}{*}{ Parameter } & \multicolumn{3}{|l|}{ Mean (SD) } \\
\hline & $\begin{array}{l}\text { Controls } \\
\text { (Acanthosis } \\
\text { Grade } 0 \text { ) } \\
\mathrm{N}=68\end{array}$ & $\begin{array}{l}\text { Acanthosis } \\
\text { Nigricans } \\
\text { Grade } 4 \\
\mathrm{~N}=32\end{array}$ & $p$ \\
\hline Age (years) & $24.36(5.44)$ & $41.50(13.32)$ & $<0.001$ \\
\hline Weight (Kg) & $63.02(14.10)$ & $94.19(17.49)$ & $<0.001$ \\
\hline Waist Circumference $(\mathrm{cm})$ & $78.29(11.34)$ & $112.02(13.21)$ & $<0.001$ \\
\hline Height (cm) & $169.78(10.06)$ & $164(10.51)$ & 0.010 \\
\hline \multirow[t]{2}{*}{$\mathrm{BMI}\left(\mathrm{kgm}^{-2}\right)$} & $21.66(3.40)$ & $34.96(5.16)$ & $<0.001$ \\
\hline & \multicolumn{3}{|l|}{$N(\%)^{*}$} \\
\hline Males & $35(52)$ & $9(28)$ & 0.033 \\
\hline \multicolumn{4}{|l|}{ Ethnicity } \\
\hline Afros/Others & $15(22)$ & $14(44)$ & \\
\hline Indos & $53(78)$ & $18(56)$ & 0.026 \\
\hline \multicolumn{4}{|l|}{ SVC assay response } \\
\hline ABSENT & $16(24)$ & $26(81)$ & \\
\hline PRESENT & $52(76)$ & $6(19)$ & $<0.001$ \\
\hline
\end{tabular}

Abbreviations: SVC = Skin vasoconstrictor assay to topical beclomethasone $\mathrm{BMI}=$ Body mass index; Afros = Africans; Indos = East Indians;

* $=$ column percentages

1 there is an obvious tendency for AN grade 4 subjects to have SVC response of grade 0 . This relationship is highly significant (Kendall's tau $-0.464, . \mathrm{p}<0.001$ ).

CRP and $A N$ and SVC

Table 6 shows the relationship between inflammatory markers for those with and without acanthosis nigricans. The level of hs-CRP was elevated in subjects with AN grade 4. There was no relationship between IL-1, IL-6, and TNF-alpha between cases and the controls. However CRP was related to baseline plasma glucose and serum triglyceride levels.

For the 100 subjects in study 1 there was significant correlation between CRP and the following variables (rho, p < 0.001): age (0.475), waist circumference (0.451), weight (0.397), AN (0.522), SVC graded as zero or above zero (-0.355). The following variables also had significant correlations with CRP (rho, p): glucose (0.226, 0.037), triglycerides $(0.347,0.001)$. CRP was not related to ethnicity $(\mathrm{p}=0.633)$ or to any other parameters assessed during the study.

Table 2 The relationship between ethnicity and acanthosis nigricans in Study $1(\mathbf{N}=\mathbf{1 0 0})$

\begin{tabular}{lllll}
\hline AN Grade 4 & \multicolumn{2}{l}{ ETHNICITY } & \multicolumn{2}{l}{ Total } \\
\cline { 2 - 5 } & AFRO & INDO & OTHER & \\
\hline Controls (No Acanthosis) & $5(29.4)$ & $53(74.6)$ & $10(83.3)$ & $68(68.0)$ \\
\hline AN Grade 4 & $12(70.6)$ & $18(25.4)$ & $2(16.7)$ & $32(32.0)$ \\
\hline Total & $\mathbf{1 7}$ & $\mathbf{7 1}$ & $\mathbf{1 2}$ & $\mathbf{1 0 0}$ \\
\hline
\end{tabular}


Table 3 The relationship between ethnicity and SVC in Study $1(N=100)$

\begin{tabular}{lllll}
\hline \multirow{2}{*}{ SVC Response } & \multicolumn{2}{l}{ ETHNICITY } & \multicolumn{2}{l}{ Total } \\
\cline { 2 - 5 } & AFRO & INDO & OTHER & \\
\hline 0 & $13(76.5)$ & $25(35.2)$ & $4(33.3)$ & $42(42.0)$ \\
\hline 1 & $0(0.0)$ & $1(1.4)$ & $0(0.00)$ & $1 \mathrm{i}(1.0)$ \\
\hline 2 & $0(0.00)$ & $1(1.4)$ & $1(8.3)$ & $2(2.0)$ \\
\hline 3 & $3(17.6)$ & $10(14.1)$ & $0(0.00$ & $13(13.0)$ \\
\hline 4 & $1(5.9)$ & $34(47.9)$ & $7(58.3)$ & $42(42.0)$ \\
\hline TOTAL & $\mathbf{1 7}$ & $\mathbf{7 1}$ & $\mathbf{1 2}$ & $\mathbf{1 0 0}$ \\
\hline
\end{tabular}

Multivariate analysis with CRP as outcome variable showed that age, triglycerides and SVC were independent predictors of serum CRP (Table 7).

Figure 2 shows that in the subgroup with AN grade 4 and the absence of an SVC, CRP was markedly elevated.

Figures 3, 4, 5 and 6 show the clinical grading of acanthosis nigricans as defined by Burke et al. [15].

\section{Study 2}

In order to elucidate the relationship of AN to SVC in more detail we studied a cross-section of diabetic patients with varying grades of AN. Of the 109 subjects studied 30 had AN (grade 0) and the other 79 had AN classified as $(\mathrm{N}=$ number $)$ : grade $1(\mathrm{~N}=24), 2(\mathrm{~N}=$ $18), 3(\mathrm{~N}=25), 4(\mathrm{~N}=12)$. Patients with AN grade 0 vs. greater than 0 had mean (SD) age 58.97 (11.54) vs. 55.61 (10.74) years, $\mathrm{p}=0.168$; weight $71.70(17.13)$ vs. 80.63 (18.66), $\mathrm{p}=0.028$; waist circumference 94.88 (10.37) vs. $105.60(18.10) \mathrm{cm}, \mathrm{p}=0.003$; BMI 26.41 (6.18) vs. 29.51 (6.44) kilogram per square metre, $\mathrm{p}=$ 0.022 . There were 40 males and 62 patients were of Asian-Indian ethnicity. Tables 4 and 5 show that there was no difference between ethnic groups in AN or SVC response. Figure 1(b) shows that there was also a highly significant trend for subjects with high grade AN to have a low grade SVC response: Kendall's tau -0.487, p $<0.001$. The magnitude of the test of trend was similar in both Study 1 and Study 2.

Table 4 The relationship between ethnicity and acanthosis nigricans in Study $2(N=107)$

\begin{tabular}{lllll}
\hline Acanthosis Nigricans Graded & \multicolumn{2}{l}{ ETHNICITY } & \multicolumn{2}{l}{ Total } \\
\cline { 2 - 5 } & AFRO & INDO & OTHER \\
\hline 0 & $9(28.1)$ & $19(28.4)$ & $2(20.0)$ & $30(27.5)$ \\
\hline 1 & $6(18.8)$ & $16(23.9)$ & $2(20.0)$ & $24(22.0)$ \\
\hline 2 & $6(18.8)$ & $10(14.9)$ & $2(20.0)$ & $18(16.5)$ \\
\hline 3 & $7(21.9)$ & $17(25.4)$ & $1(10.0)$ & $25(22.9)$ \\
\hline 4 & $4(12.5)$ & $5(7.5)$ & $3(30.0)$ & $12(11.0)$ \\
\hline TOTAL & $\mathbf{3 2}$ & $\mathbf{6 7}$ & $\mathbf{1 0}$ & $\mathbf{1 0 9}$ \\
\hline
\end{tabular}

Table 5 The relationship between ethnicity and SVC in Study 2 ( $N=107)$.

\begin{tabular}{lllll}
\hline SVC Response & \multicolumn{2}{l}{ ETHNICITY } & \multicolumn{2}{l}{ Total } \\
\cline { 2 - 5 } & AFRO & INDO & OTHER \\
\hline 0 & $19(59.4)$ & $36(54.5)$ & $5(55.6)$ & $60(56.1)$ \\
\hline 1 & $4(12.5)$ & $5(7.60$ & $0(0.00$ & $9(8.4)$ \\
\hline 2 & $1(3.1)$ & $1(1.5)$ & $1(11.1)$ & $3(2.8)$ \\
\hline 3 & $3(9.4)$ & $6(9.1)$ & $1(11.1)$ & $10(9.3)$ \\
\hline 4 & $5(15.6)$ & $18(27.3)$ & $2(22.1)^{\prime}$ & $25(23.4)$ \\
\hline TOTAL & $\mathbf{3 2}$ & $\mathbf{6 6}$ & $\mathbf{9}$ & $\mathbf{1 0 7}$ \\
\hline
\end{tabular}

See text for further details

\section{Discussion}

Acanthosis nigricans (AN) was first recognized more than 100 years ago in association with internal malignancy. In 1976, in a landmark study Kahn et al [17] described what has become today, its commonest association - the link with insulin resistance and type 2 diabetes. Thus individuals with $\mathrm{AN}$ are more likely to display risk factors for type 2 diabetes whatever their ethnic or geographic origin $[18,19]$.

Fifty years ago, it was observed in the course of treating skin diseases with topical glucocorticoids that pallor of the surrounding skin occurred [20], an observation that has formed the basis of the skin vasoconstrictor assay (SVC). Traditionally used to evaluate the potential efficacy of newer topical glucocorticoid agents, workers have explored the potential of this bioassay to assess glucocorticoid sensitivity as a pathogenetic mechanism for disease [16,21].

Individual responsiveness to topically applied glucocorticoid varies considerably such that there are individuals who respond with an intense degree of pallor and others who only barely do so or not at all [22]. In a previous study [23] we were intrigued by the heterogeneity of this biologic response to topically applied glucocorticoid and asked whether a lack of response reflected a more generalized insensitivity to glucocorticoids. We demonstrated that patients defined as having asthma resistant to standard therapeutic doses of systemic glucocorticoid were more likely to demonstrate reduced skin vasoconstrictor responsiveness to potent topically applied glucocorticoid [16]. These findings supported the concept that topical glucocorticoid resistance was an indicator a more generalised phenomenon. In further work, topically applied progesterone or aldosterone failed to produce a SVC response and additionally, the response to potent glucocorticoid was abolished by specific glucocorticoid receptor blocking agents [24]. These observations permitted the conclusion that the SVC response is specifically glucocorticoid receptor mediated and its absence may point to evidence of disturbance of glucocorticoid pharmacodynamics and receptor activation rather than altered 
(a)

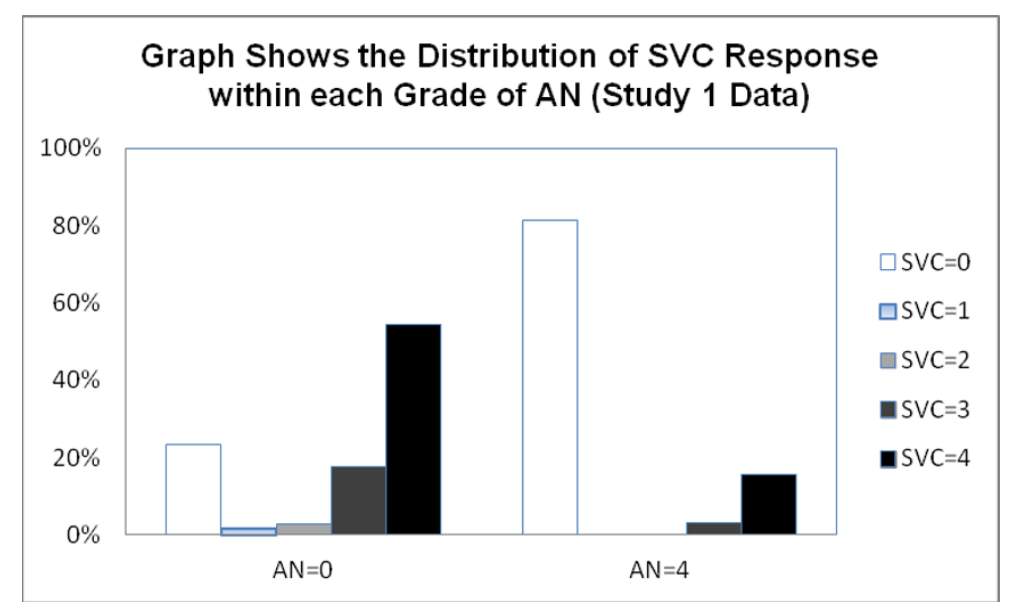

(b)

Graph Shows the Distribution of SVC Response within each Grade of AN (Study 2 Data)

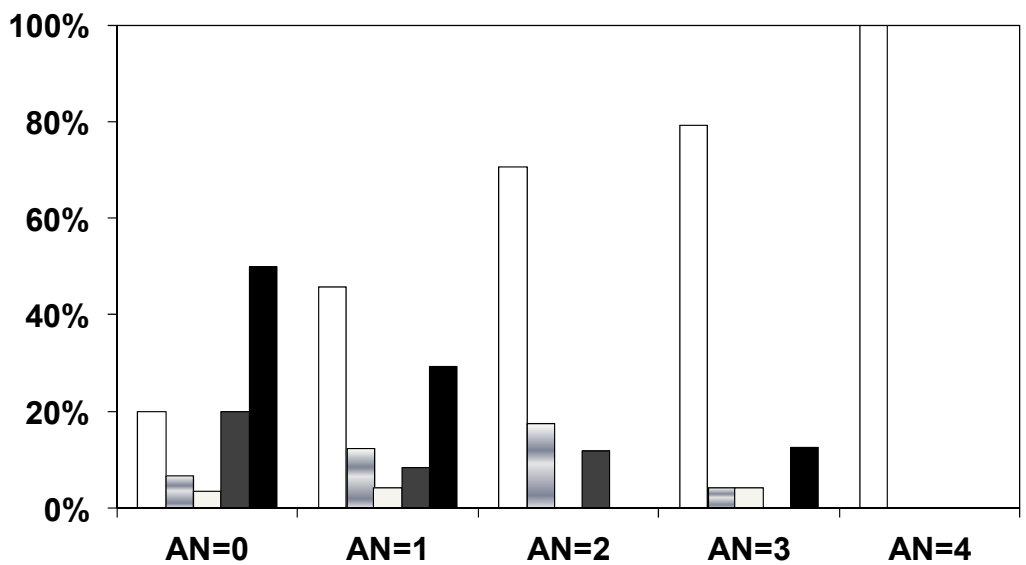

Figure 1 (a) Graph Shows the Distribution of SVC Response within each Grade of AN (Study 1 Data). (b) Graph Shows the Distribution of SVC Response within each Grade of AN (Study 2 Data).

Table 6 Inflammatory markers, fasting glucose and triglycerides in controls and subjects with acanthosis nigricans grade 4 (Study $1, N=100$ )

\begin{tabular}{|c|c|c|c|c|}
\hline \multirow[t]{2}{*}{ Parameter } & \multirow[t]{2}{*}{$\mathbf{N}$} & \multicolumn{2}{|c|}{ Median (Interquartile Range) } & \multirow[t]{2}{*}{$\mathbf{p}^{*}$} \\
\hline & & Control & Acanthosis Grade 4 & \\
\hline C-reactive protein (mg/L) & 100 & $\begin{array}{l}5.00(0.00,6.00) \\
n=32\end{array}$ & $\begin{array}{l}11.00(6.25,24.75) \\
n=68\end{array}$ & $<0.001$ \\
\hline IL1 (pg/ml) & 79 & $7.66(0.20,25.05)$ & $3.17(0.13,12.95)$ & 0.309 \\
\hline IL6 (pgml) & 89 & $35.2(22.2,53.9)$ & $30.1(13.1,42.8)$ & 0.287 \\
\hline TNF-alpha (pg/ml) & 88 & $8.52(6.88,14.00)$ & $9.07(8.12,11.74)$ & 0.603 \\
\hline Fasting Glucose (mg/dl) & 86 & $79(74,84)$ & $90(77,111)$ & 0.011 \\
\hline Triglycerides (mg/dl) & 87 & $82(64,104)$ & $140(82,189)$ & $<0.001$ \\
\hline
\end{tabular}

* Mann Whitney U Test 
Table 7 Parameter estimates for a generalized linear model with C-reactive protein as outcome variables

\begin{tabular}{llllll}
\hline Parameter & B & Std. Error & Sig. & \multicolumn{2}{c}{ 95\% Confidence Interval } \\
& & & & Lower Bound & Upper Bound \\
\hline Intercept & 1.18 & 6.56 & 0.858 & -11.90 & 14.26 \\
BMI & -0.38 & 0.28 & 0.181 & -0.94 & 0.18 \\
Age (years) & 0.29 & 0.09 & 0.002 & 0.11 & 0.48 \\
Glucose (mg/dl) & -0.02 & 0.03 & 0.397 & -0.08 & 0.03 \\
Triglycerides (mg/dl) & 0.04 & 0.02 & 0.008 & 0.01 & 0.08 \\
Waist Circumference (cm) & 0.04 & 0.09 & 0.673 & -0.15 & 0.23 \\
Acanthosis nigricans Grade 0 & -0.64 & 3.32 & 0.847 & -7.26 & 5.98 \\
SVC & 10.37 & 3.04 & 0.001 & 4.31 & 16.42 \\
Acanthosis nigricans * SVC & 10.10 & 3.39 & 0.004 & -16.86 & -3.34 \\
\hline
\end{tabular}

Abbreviations: SVC = Skin vasoconstrictor assay to topical beclomethasone dipropionate;

$\mathrm{BMI}=$ Body mass index; ${ }^{{ }^{* \prime} \prime}=$ interaction

glucocorticoid pharmacokinetics. In further support of this idea, there are data which have linked variation in skin vasoconstrictor responsiveness to polymorphism in the glucocorticoid receptor gene [25].

In the current study, we have now demonstrated a novel clinical observation linking AN to the absence of the SVC response. Thus the greater the degree of AN, the less likely was there an SVC response to beclomethasone dipropionate. There is a number of possible explanations for this finding. Firstly, in AN, the skin is thickened and an absent biologic response could simply be the result of poor bioavailability across thickened skin. Against this idea would be the fact that the agent used in this study, beclomethasone dipropionate, is potent, exhibits high cutaneous bioavailability [26] and which was, in addition, used in high concentration. It is also

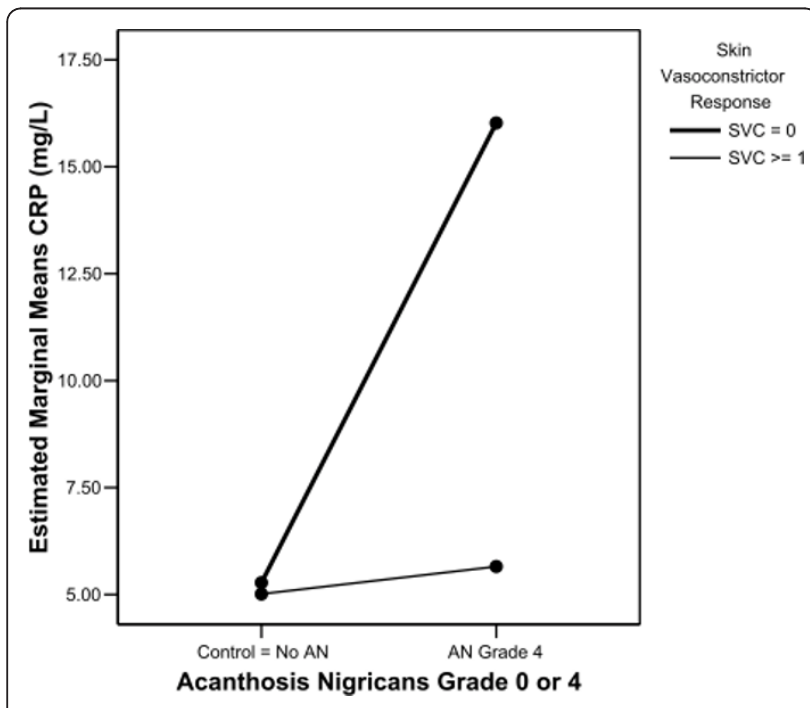

Figure 2 Model estimated marginal means of C-reactive protein at different levels of skin vasoconstrictor response to topical beclomethasone dipropionate(SVC). SVC is classified as not present at all $(=0)$ or present $(>=1)$ for patients with and without acanthosis nigricans [Study 1]. noteworthy that the sites of predilection for AN (neck, axillae and groin) were quite remote from the site where the SVC assay was conducted viz., the volar aspect of the forearm. Another possible explanation is that SVC may be diminished in darker skin. However, we have found that SVC was independent of ethnic origin (Study 2) in which peoples of African, South Asian or mixed ancestry participated and which provided a range of skin textures and colours. The alternative explanation is that there is reduced glucocorticoid sensitivity of dermal vasculature among severely insulin -resistant individuals as characterized by high grade AN. Such reduced glucocorticoid action would provide a plausible explanation as to why in the face of increased cortisol exposure in MS [13,14] characteristic Cushingoid features, notably thin skin and purpura are absent. Differential tissue sensitivity will also explain another paradox.

One of the models of MS that has been recently explored is that relating to over activity of an enzyme, 11beta-hydroxysteroid dehydrogenase type 1 , which regenerates the natural active glucocorticoid cortisol in man (corticosterone in rodents) from inactive cortisone (deoxycorticosterone in rodents). Mice over expressing the gene for this enzyme in adipose tissue have metabolic and phenotypic features of MS [27]. Treatment with a specific inhibitor of the enzyme both reverses the metabolic abnormalities of MS as well as also stops atherosclerotic plaque progression [28]. The mouse model of MS in which glucocorticoid is overproduced in some tissues is not mutually exclusive of the findings demonstrated in our study. In man the enzyme 11B-hydroxysteroid dehydrogenase is active in mature adipocytes and hepatocytes and may play a role in increasing glucocorticoid activity locally in obesity syndromes [13]. Our work suggests that in the face of increased glucocorticoid production in the liver and adipose tissue reduced dermal glucocorticoid sensitivity may exemplify a possible adaptive mechanism response to counteract glucocorticoid overexposure i.e. tissueselective glucocorticoid resistance. In this regard, it is well 


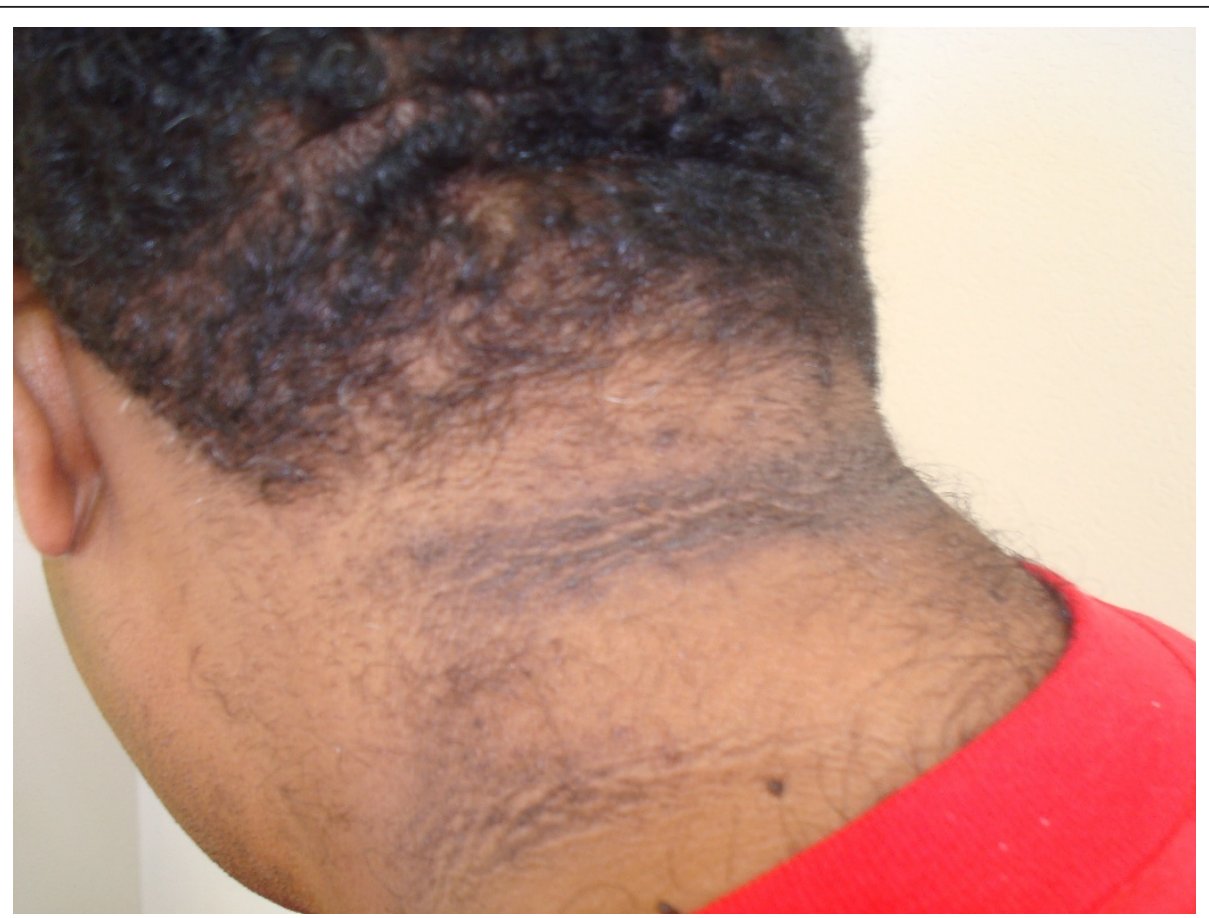

Figure 3 Acanthosis nigricans Grade 1.

recognized that tissues can differentially regulate glucocorticoid exposure both by enzyme-mediated [29] as well as receptor-mediated mechanisms [30].
Glucocorticoid resistance, even if adaptive, will have consequences. Given the natural anti-inflammatory actions of glucocorticoids one would expect that

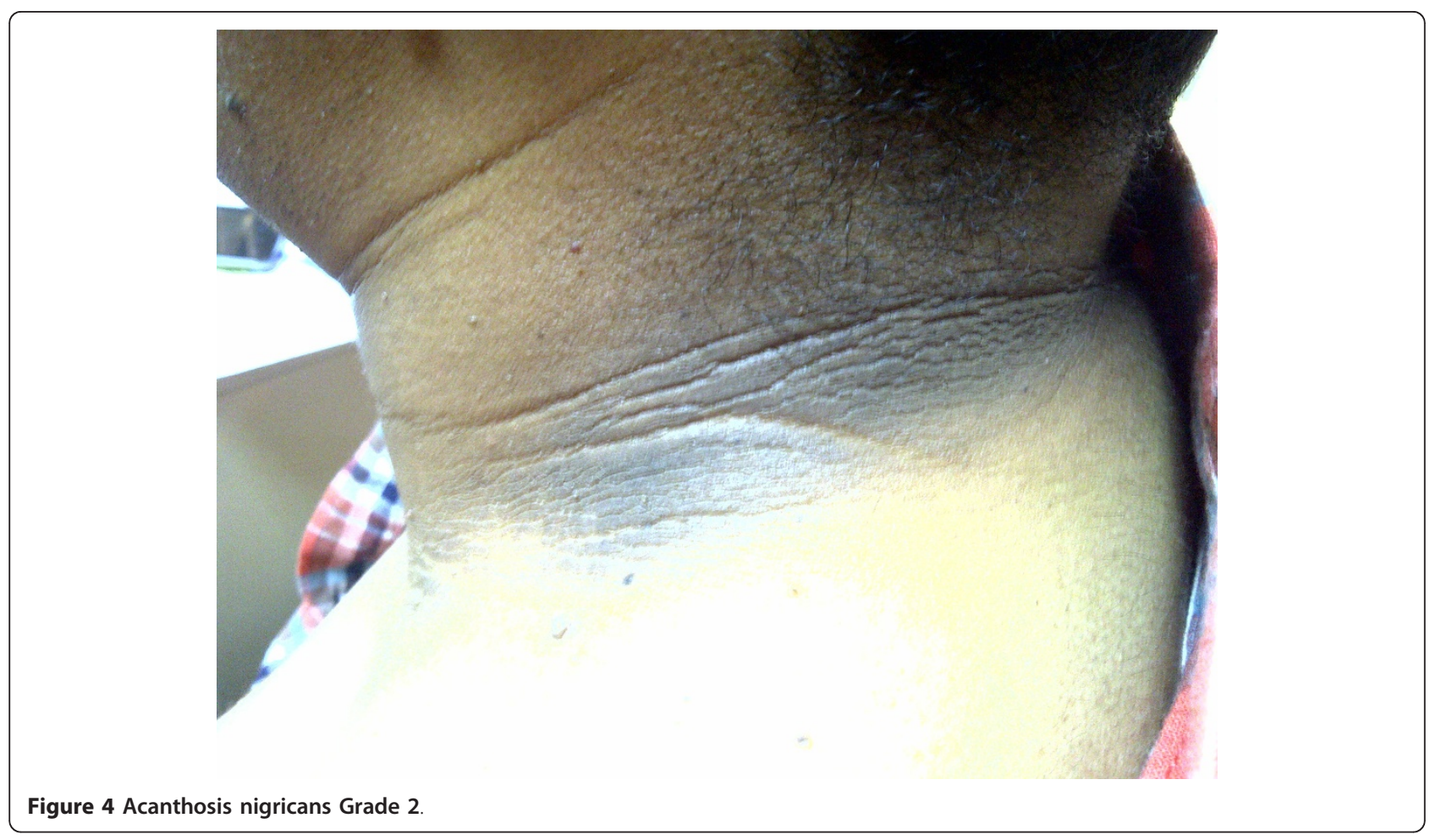




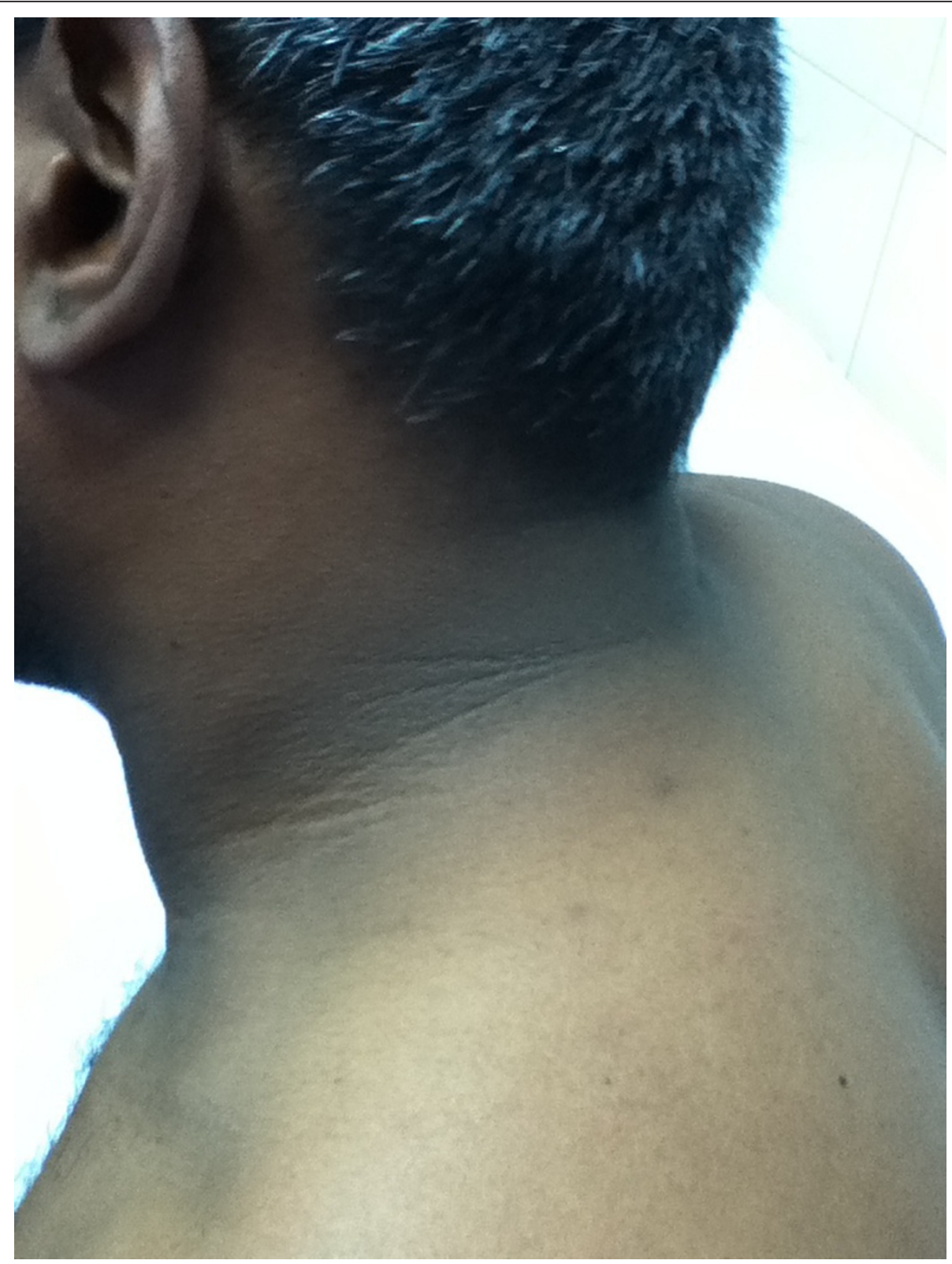

Figure 5 Acanthosis nigricans Grade 3

inflammatory phenomena could arise from this state of reduced glucocorticoid activity. In keeping with this notion, we have shown that not only was SVC an independent predictor of CRP but also those with combined AN and absent SVC have the highest CRP levels (Figure 2 ). The role of the vasculature in the immune response is well documented [31] and elevated CRP reflects deficiency of the innate immune system. It should be noted, however, there was no obvious relationship between plasma cytokines IL-1, IL-6 and TNF-alpha and the SVC among the groups here studied. This implies that the exaggerated inflammatory response, though more marked when SVC is absent, is confined to innate or vascular mechanisms without discernible changes involving cytokines.

There were some limitations to our studies. There was an age disparity between subjects carefully selected for having high grade AN in STUDY 1 when compared with controls which could have been a confounding factor. In the multivariate linear model which is based on data from study 1, the interaction between SVC and AN may also be mediated by those other covariates which are imbalanced between the groups with and without AN grade 4. However, in STUDY 2, where subjects were 


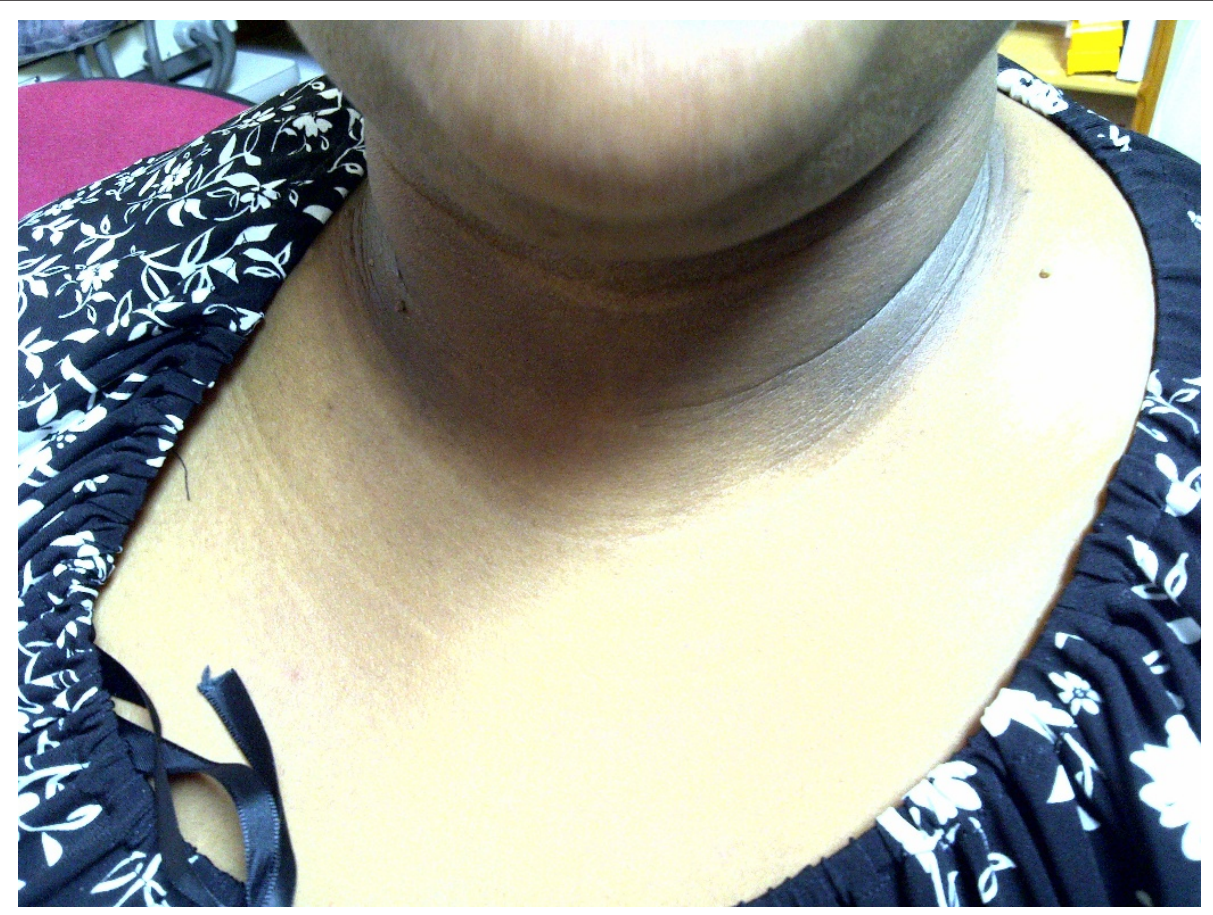

Figure 6 Acanthosis nigricans Grade 4.

drawn cross-sectionally and in which there were no significant age difference in the groups, the association between AN and absent SVC was sustained. Similarly, analysis of data to evaluate the relationship between SVC and ethnicity would not have been meaningful in Study 1 , given the small numbers of Afro-Caribbeans $(n=17)$ and "Others" $(\mathrm{n}=10)$ but in Study 2 where this was possible, we found SVC to be independent of ethnicity. The prevalence of AN is known to be ethnically related and darker races exhibit higher prevalence [18]. It remains to be seen if the SVC/AN relationship demonstrated among Africans and Asian Indians occurs in other ethnic groups. It should be noted that the frequency of SVC responsiveness also appears to be higher in Caucasians (90\%) [16] than among this sample comprising people with darker skin. It is also unclear whether the absence of SVC response to topical glucocorticoid represents a consequence of inflammation or is indeed the cause of exaggerated inflammation.

The observation that acanthosis nigricans ameliorates with progressive weight reduction [32] highlights the role of obesity in its pathogenesis. It would be interesting to determine whether SVC alters with weight reduction, which will indicate that glucocorticoid resistance in MS is acquired and not genetic with obvious implications for interventional strategies.

The interactions between stress, inflammation, obesity and the hypothalamic-pituitary-adrenal axis [7-10,33] are complex and no doubt an evolving story. Differential tissue sensitivity to glucocorticoids adds an additional dimension to the list of abnormalities already known to exist in the hypothalamic-pituitary-adrenal axis $[11,13,14,34]$ in the MS and the skin presents a valuable and practical window through which such interactions can be explored.

\section{Abbreviations}

AN: Acanthosis nigricans; SVC: Skin vasoconstrictor assay; BMI: Body mass index; MS: Metabolic syndrome; T2DM: Type 2 diabetes mellitus; hs-CRP: Highly sensitive C-reactive protein

\section{Acknowledgements}

Dr Karlene Mitchell and Dr Sherry Sandy assisted in data gathering. Ms Ria Ramdeen and Ms Angela Rooplal performed the laboratory analyses. Siana and Siara Teelucksingh assisted in preparation of the manuscript. This work was supported by a financial grant obtained from The Government of the Republic of Trinidad and Tobago. Prof CRW Edwards and Dr WF Young kindly reviewed the manuscript.

\section{Author details}

'Department of Clinical Medical Sciences, The University of the West Indies St Augustine, Trinidad \& Tobago.W.I. ${ }^{2}$ Department of Pre-Clinical Medical Sciences, The University of The West Indies. St Augustine, Trinidad \& Tobago. W.I. ${ }^{3}$ Department of Para-Clinical Medical Sciences, The University of the West Indies. St Augustine, Trinidad and Tobago.W.I.

\section{Authors' contributions}

ST, TS and LPP conceptualized, designed the studies and wrote this paper. ST performed the skin vasoconstrictor assays. SJ led the clinical work and SN performed the biochemical analyses. All authors read and approved the final manuscript.

\section{Competing interests}

The authors declare that they have no competing interests. 
Received: 30 December 2011 Accepted: 30 March 2012

Published: 30 March 2012

\section{References}

1. Hossain P, Kawar B, El Nahas M: Obesity and diabetes in the developing world- a growing challenge. New Engl J Med 2007, 356:213-215.

2. Enzi G, Busetto L, Inelman EM, Coin A, Sergi G: Historical perspective: visceral obesity and related comorbidity in Joannes Baptista Morgagni's "De Sedibus et causis morborum per anatomen indagata". J Obes 2003, 27:534-535.

3. Reaven GM: Banting Lecture 1988. Role of insulin resistance in human disease. Diabetes 1988, 37(12):1595-1607.

4. Grundy SM: Metabolic syndrome pandemic. Arterioscler Thromb Vasc Biol 2008, 28(4):629-636.

5. Gerstein HC: More insights on the dysglycaemia-cardiovascular connection. Lancet 2010, 375:2195-2196.

6. Stern MP: Diabetes and cardiovascular disease. The "common soil" hypothesis. Diabetes 1995, 44:369-374.

7. Sam S, Feinstein S, Haffner S, Kondos G, Davidson MH, Perez A, et al: Relation of abdominal fat depots to systemic markers of inflammation in Type 2 Diabetes. Diabetes Care 2009, 32:932-937.

8. Kolb H, Mandrup-Poulsen T: The global diabetes epidemic as a consequence of lifestyle-induced low grade inflammation. Diabetologia 2010, 53:10-20.

9. Pickup JC: Inflammation and activated innate immunity in the pathogenesis of Type 2 diabetes. Diabetes Care 2004, 27(3):813-823.

10. Tataranni PA, Ortega E: A burning question: does an adipokine-induced activation of the immune system mediate the effect of overnutrition on type 2 diabetes? Diabetes 2005, 54:917-927.

11. Walker BR: Cortisol- cause and cure for metabolic syndrome? Diabet Med 2008, 23:1281-1288.

12. van den Akker EL, Koper JW, van Rossum EFC, Dekker MJH, Russcher H, de Jong $\mathrm{FH}$, et al: Glucocorticoid receptor gene and risk of cardiovascular disease. Arch Intern Med 2008, 168:33-39.

13. Seckl JR, Morton NM, Chapmen KE, Walker BR: Glucocorticoids and 11 beta-hydroxysteroid dehydrogenase in adipose tissue. Recent Prog Horm Res 2004, 59:359-393.

14. Anagnostis P, Athros VG, Tziomalos K, Karagiannis A, Mikhailidis DP: The pathogenetic role of cortisol in the metabolic syndrome: a hypothesis. J Clin Endocrinol Metab 2009, 94:2692-2701.

15. Burke JP, Hale DE, Hazuda HP, Stern MP: A quantitative scale of acanthosis nigricans. Diabetes Care 1999, 22:1655-1659.

16. Brown PH, Teelucksingh S, Matusiewicz SP, Greening AP, Crompton GK, Edwards CRW: Cutaneous vasoconstrictor response to glucocorticoids in asthma. Lancet 1991, 337:576-580.

17. Kahn CR, Flier JS, Bar RS, Archer JA, Gorden P, Martin MM, et al: The syndromes of insulin resistance and acanthosis nigricans. Insulinreceptor disorders in man. New Engl J Med 1976, 294:739-745.

18. Stuart CA, Gilkison CR, Keenan BS, Nagamani M: Hyperinsulinemia and acanthosis nigricans in African Americans. J Natl Med Assoc 1997, 89(8):523-527.

19. Pinheiro AC, Rojas P, Carrasco F, Gomez P, Mayas N, Morales I: Acanthosis nigricans as an indicator of insulin resistance in Chilean adult population. Nutr Hosp 2011, 26(5):940-944.

20. McKenzie AW, Stoughton RB: Method for comparing percutaneous absorption of steroids. Arch Dermatol 1962, 86:608-610.

21. Walker BR, Best R, Shackleton CHL, Padfield P, Edwards CRW: Increased v asoconstrictor sensitivity to glucocorticoids in essential hypertension. Hypertension 1996, 27:190-196.

22. Barry BW, Woodford R: Activity and bioavailability of topical steroids: In vivo/in vitro correlations for the vasoconstrictor test. J Clin Pharmac 1978, 3:43-65.

23. Teelucksingh S, Mackie ADR, Burt D, McIntyre MA, Brett L, Edwards CRW: Potentiation of hydrocortisone activity in skin by glycyrrhetinic acid. Lancet 1990, 335:1060-1063.

24. Teelucksingh S: Glucocorticoids and the skin. PhD thesis University of Edinburgh, Scotland; 1995.

25. Panarelli M, Holloway CD, Fraser R, Connell JMC, Ingram MC, et al: Glucorticoid receptor polymorphism, skin vasoconstriction, and other metabolic intermediate phenotypes in normal human subjects. J Clin Endocrinol Metab 1998, 83:1846-1852.
26. Johansson S-A, Andersson K-E, Brattsand R, Gruvstav E, Hedner P: Topical and systemic potencies of budesonide and beclomethasone dipropionate in man. Eur J Clin Pharmacol 1982, 22:523-529.

27. Masuzaki H, Paterson J, Shinyama H, Morton NM, Mullins JJ, Seckl JR, Flier JS: A transgenic model of visceral obesity and the metabolic syndrome. Science 2001, 294(5549):2166-2170

28. Hermanowski-Vosatka A, Balkovec JM, Cheng K, Chen HY, Hernandez M, Koo GC, Legrand CB, et al: 11 beta-hydroxsteroid dehydrogenase 1 inhibition ameliorates metabolic syndrome and prevents progression of atherosclerosis in mice. J Exp Med 2005, 202(4):517-527.

29. Edwards CR, Benediktsson R, Lindsay RS, Seckl JR: 11 beta-hydroxysteroid dehydrogenases: Key enzymes in determining tissue-specific glucocorticoid effects. Steroids 1996, 61(4):263-269.

30. Freeman Al, Munn HL, Lyons V, Dammermann A, Seckl JR, Chapman KE: Glucocorticoid down-regulation of rat glucocorticoid receptor does not involve differential promoter regulation. J Endocrinol 2004, 183(2):365-374.

31. Hansson GK, Libby P, Schonbeck U, Yan Z-Q: Innate and adaptive immunity in the pathogenesis of atherosclerosis. Circ Res 2002, 91:281-291.

32. Manco M, Castagneto M, Nanni G, Guidone C, Tondolo V, Greco AV, et al: Biliopancreatic diversion as a novel approach to the HAIR-AN syndrome. Obes Surg 2005, 15:286-289.

33. Martin-Cordero $L$, et al: The interleukin- 6 and noradrenaline mediated inflammation-stress feedback mechanism is dysregulated in metabolic syndrome: Effect of exercise. Cardiovasc Diabetol 2011, 10:42.

34. Bujalska IJ, Kumar S, Stewart PM: Does central obesity reflect "Cushing's disease of the omentum". Lancet 1997, 349:1210-1213.

doi:10.1186/1475-2840-11-31

Cite this article as: Teelucksingh et al: Does insulin resistance co-exist with glucocorticoid resistance in the metabolic syndrome? Studies comparing skin sensitivity to glucocorticoids in individuals with and without acanthosis nigricans. Cardiovascular Diabetology 2012 11:31.

\section{Submit your next manuscript to BioMed Central and take full advantage of:}

- Convenient online submission

- Thorough peer review

- No space constraints or color figure charges

- Immediate publication on acceptance

- Inclusion in PubMed, CAS, Scopus and Google Scholar

- Research which is freely available for redistribution

Submit your manuscript at www.biomedcentral.com/submit
C Biomed Central 